\title{
Surgery for anomalous aortic origin of a coronary artery: More is better?
}

Scott M. Bradley, MD

See related article on pages 422-4.

In this issue of the Journal, Dekel and colleagues ${ }^{1}$ from the Hospital for Sick Children, Toronto, describe a technique for the repair of anomalous aortic origin of a coronary artery (AAOCA). Their brief technical report includes 4 patients. The technique includes a combination of unroofing and unflooring (patch angioplasty of the antiaortic side of the coronary, opposite the unroofing). They point out that an important technical point is to carry the unflooring patch distal to the area of unroofing. In 2 of the 4 patients, the operation also included coronary reimplantation. This approach was successful in all 4 patients, although postoperative evaluation was limited to echocardiography in the operating room. Dekel and colleagues' combination approach is novel and will be of interest to surgeons operating on this defect in both children and adults.

Currently, the most commonly used technique for repair of AAOCA is isolated unroofing. ${ }^{2}$ Dekel and colleagues' dissatisfaction with unroofing motivated their exploration of this alternative approach. To be sure, unroofing does have its issues. In the operating room, it can be difficult to determine the end point of the unroofing, the exact point at which the coronary artery and the aorta diverge. In part as a consequence of this difficulty, unroofing often includes the placement of tacking sutures at its distal extent to approximate the intima of the coronary and the aorta. ${ }^{1}$ These sutures carry some risk of coronary distortion and narrowing. Unroofing can be particularly unsatisfying in a small coronary artery, such as a nondominant right coronary artery. Finally, the coronary artery often runs behind or adjacent to the left-right commissure of the aortic valve; unroofing may then entail a risk, albeit low, of aortic insufficiency.

Dekel and colleagues' combination approach in turn raises some issues of its own. If sutures are placed at the end of

\footnotetext{
From the Section of Pediatric Cardiac Surgery, Medical University of South Carolina, Charleston, SC

Disclosures: Author has nothing to disclose with regard to commercial support.

Received for publication May 23, 2015; accepted for publication May 26, 2015; available ahead of print June 24, 2015.

Address for reprints: Scott M. Bradley, MD, Section of Pediatric Cardiac Surgery, Medical University of South Carolina, 96 Jonathan Lucas St, CSB 424, Charleston, SC 29425-1095 (E-mail: bradlesm@ @usc.edu).

J Thorac Cardiovasc Surg 2015;150:425-6

$0022-5223 / \$ 36.00$

Copyright (c) 2015 by The American Association for Thoracic Surgery http://dx.doi.org/10.1016/j.jtcvs.2015.05.060
}

the unroofing incision, the combination approach will result in a series of sutures on both sides of the coronary at $180^{\circ}$ to each other. The sutures, along with the patch material, will carry some risk of technical error and distortion, as well as late neointimal proliferation and stenosis. Because the un-

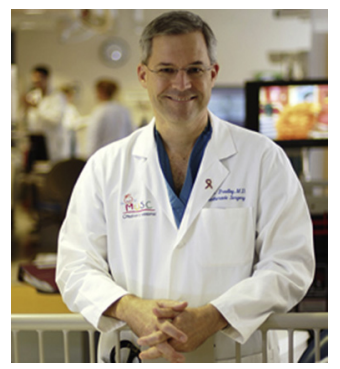
flooring patch extends beyond the unroofing incision, it is not clear that the unroofing is necessary; would unflooring by patching alone, without unroofing, achieve the same end result? ${ }^{4,5}$ The decision to add reimplantation to the operation is based on evaluation of potential coronary compression between the great vessels. This "eyeball test" seems subjective and perhaps difficult to apply consistently. Finally, reimplantation, when used, may involve takedown and resuspension of an aortic valve commissure, which could affect valve competence.

Surgery for AAOCA has both short-term, technical aims, and long-term, physiologic aims. The technical aims are to fashion a widely patent coronary ostium, to create a coronary path that is not subject to distortion or compression by the great vessels, and to maintain a competent aortic valve. The physiologic aims are to avoid myocardial ischemia and sudden death. The variety of technical approaches to achieve these aims indicates a lack of consensus in the field, both because of the wide variations in coronary morphology and because of the lack of significant long-term follow-up in previous series. As Dekel and colleagues point out, evaluation of this and other techniques will require decades of follow-up. Some of this information will be forthcoming from the Congenital Heart Surgeons' Society registry of patients with AAOCA. ${ }^{6}$ Dekel and colleagues do have an opportunity to assess their small cohort by computed tomographic angiography in 9 to 12 months, which would provide a valuable follow-up evaluation of the technical adequacy of their combination approach.

\section{References}

1. Dekel H, Hickey EJ, Wallen J, Caldarone CA. Repair of anomalous aortic origin of coronary arteries with combined unroofing and unflooring technique. J Thorac Cardiovasc Surg. 2015;150:422-4

2. Poynter JA, Bondarenko I, Austin EH, DeCampli WM, Jacobs JP, Ziemer G, et al; Congenital Heart Surgeons' Society AAOCA Working Group. Repair of anomalous aortic origin of a coronary artery in 113 patients: a Congenital Heart Surgeons' Society Report. World J Pediatr Congenit Heart Surg. 2014;5: 507-14. 
3. Romp RL, Herlong JR, Landolfo CK, Sanders SP, Miller CE, Ungerleider RM, et al. Outcome of unroofing procedure for repair of anomalous aortic origin of left or right coronary artery. Ann Thorac Surg. 2003;76:589-95; discussion 595-6.

4. Karl TR, Provenzano SC, Nunn GR. Anomalous aortic origin of a coronary artery: a universally applicable surgical strategy. Cardiol Young. 2010;20(Suppl 3):44-9.
5. Gaudin R, Raisky O, Vouhé PR. Anomalous aortic origin of coronary arteries: 'anatomical' surgical repair. Multimed Man Cardiothorac Surg. 2014;2014:mmt022.

6. Poynter JA, Williams WG, McIntyre S, Brothers JA, Jacobs ML, Congenital Heart Surgeons Society AAOCA Working Group. Anomalous aortic origin of a coronary artery: a report from the Congenital Heart Surgeons Society Registry. World J Pediatr Congenit Heart Surg. 2014;5:22-30. 